Discussion Paper No. 03-24

\title{
Publicly Funded R\&D Collaborations and Patent Outcome in Germany
}

Dirk Czarnitzki and Andreas Fier

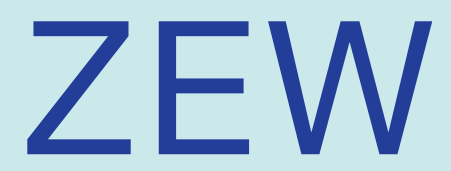

Zentrum für Europäische Wirtschaftsforschung GmbH

Centre for European

Economic Research 
Discussion Paper No. 03-24

\title{
Publicly Funded R\&D Collaborations and Patent Outcome in Germany
}

\author{
Dirk Czarnitzki and Andreas Fier
}

Download this ZEW Discussion Paper from our ftp server:

ftp://ftp.zew.de/pub/zew-docs/dp/dp0324.pdf

Die Discussion Papers dienen einer möglichst schnellen Verbreitung von neueren Forschungsarbeiten des ZEW. Die Beiträge liegen in alleiniger Verantwortung der Autoren und stellen nicht notwendigerweise die Meinung des ZEW dar.

Discussion Papers are intended to make results of ZEW research promptly available to other economists in order to encourage discussion and suggestions for revisions. The authors are solely responsible for the contents which do not necessarily represent the opinion of the ZEW. 


\section{Non-technical Summary}

At the European Council in Lisbon in March 2000, heads of state and governments set the European Union the ambitious goal of becoming "the most competitive and dynamic knowledge-based economy in the world by the end of the decade". Two years later the Council reaffirmed this goal in Barcelona and added it to a more specific but equally ambitious target of raising EU spending on research and development to $3 \%$ of GDP by 2010 - with two thirds of this spend by the business sector.

From the perspective of innovation, public R\&D spending is an input factor which should strengthen the European Union's competitiveness in future technologies. In this context, the question arises, whether public R\&D spending enlarges the welfare of societies. An analysis of such a question requires an identification of input-output relationships between publicly funded R\&D activities and their results, like patent outcome or commercialized products and services as well as cost reducing processes. In this paper we investigate patent applications of firms. As the stimulation of R\&D cooperations and networks has become very popular in technology policies of the EU, we focus our analysis especially on R\&D collaborations at the firm level.

First, we describe the history of public R\&D funding in Germany and the development of measures encouraging collaborative R\&D activities among firms and public research institutions. Afterwards, we investigate empirically the impact of such measures on patenting activity at the firm level. The main issue of our analysis is to distinguish three different groups of firms: (i) non-collaborating companies, (ii) collaborating firms which are involved in publicly funded R\&D consortia, (iii) firms with only privately financed $R \& D$ collaborations.

We use a sample of 4,132 observations on German firms from the 1990s and apply Probit estimations on the propensity to patent as well as a count data model on the number of granted patents. In a further step, we carry out a non-parametric kernel-based matching to take account of a possible self-selection bias in the sample of publicly funded firms. The microeconometric results show that collaborating firms are more likely to patent than non-collaborating firms. This points to the existence of knowledge flows which generate positive spillover effects among network partners. Within the group of collaborating firms, participants in publicly sponsored R\&D consortia exhibit a higher probability to patent than firms in non-sponsored networks. Especially SMEs seem to benefit from spillovers which makes their application for patents more likely. A reason for this result might be determined by the official funding guidelines and the pressure of the granting institutions who force the participants to utilize their research results within a time period of two years after completion of the funded research projects. 


\title{
Publicly Funded R\&D Collaborations and Patent Outcome in Germany
}

\author{
Dirk Czarnitzki and Andreas Fier* \\ Centre for European Economic Research (ZEW), Mannheim \\ First Version: May 2003 \\ Revised: March 2004
}

\begin{abstract}
The stimulation of co-operations has become very popular in R\&D policies in recent years. This paper describes the history of R\&D funding in Germany with a focus on the development of measures encouraging collaborative $\mathrm{R} \& \mathrm{D}$ activities among firms and public research institutions. We investigate empirically the impact of such measures on patenting activity at the firm level. The microeconometric results show that collaborating firms are more likely to patent than others. Within the group of collaborating firms, participants in publicly sponsored R\&D consortia exhibit a higher propensity to patent than firms in non-sponsored networks.
\end{abstract}

Keywords: $\quad$ R\&D, Public Subsidies, Collaboration, Policy Evaluation JEL-Classification: C14, C25, H50, O38

Address: $\quad$ Centre for European Economic Research (ZEW) Department of Industrial Economics and International Management P.O.Box 103443 68034 Mannheim Germany

Phone: $\quad+49 / 621 / 1235-158,-180$

Fax: $\quad+49 / 621 / 1235-170$

E-mail: czarnitzki@zew.de, fier@zew.de

\footnotetext{
* We are grateful to the German Federal Ministry for Education and Research (BMBF) for providing the database on public R\&D funding. Moreover, we thank Oded Bizan, Koenraad Debackere, Dietmar Harhoff, Guido Imbens, Saul Lach, Georg Licht, Christian Rammer, Reinhilde Veugelers and the participants of several conferences for helpful comments.
} 


\section{Introduction}

Governments in the world emphasize the need to improve the transfer of know-how throughout the innovation system. One of the main issues in this context is collaboration between science and industry to strengthen the national innovation capabilities. Nowadays, firms acquire technological knowledge outside their organizational boundaries to reduce innovation costs, to decrease time to market and/or leap-frog existing technologies (Link, 2002). In most OECD countries public measures are directed to bring private organizations and public research institutions closer together, providing researchers and projects with skills and incentives to take their ideas to the market (cf. OECD, 2002). The main focus of co-operative $R \& D$ policies is to exchange expertise among performers, primarily between academic scientists and industrial researchers in order to improve the contribution of scientists on technological capabilities, and to support innovations and patent activities.

Today's governments search for effective compositions of technology policy instruments, such as fiscal measures, credits or subsidies which are most promising for future growth. "If technological innovation is called the most important force driving economic growth, then public policies designed to promote and encourage technological innovation take on substantial importance” (Branstetter/Sakakibara, 2002). Recently, the European Commission has introduced networks of excellence in the $6^{\text {th }}$ Framework Programme. Multipartner projects are aimed at strengthening the European excellence on a research topic by combining resources and expertise. "This expertise will be networked around a joint programme of activities aimed primarily at creating a progressive and lasting integration of the research activities of the network partners, while at the same time advancing knowledge on the topic" (European Commission, 2002). In this line, research and innovation policies have recognized that publicly funded collaborations and R\&D networks are promising to strengthen the national competitiveness. Following these discoveries, traditional instruments to stimulate private and public R\&D activities have been enlarged by new modes, such as contests and research networks which are characterized by a large number of partners.

Germany was one of the first countries in Europe which offered intensive co-operative R\&D funding in the early 1980s and which introduced co-operative network competitions for public funding in the 1990s. This study tries to shed some light on the reasonable question on the return on that investment: What are the benefits of public incentives for R\&D collaborations in terms of innovative output?

In the following section we summarize theoretical and empirical evidence on networks, alliances and partnerships in the innovation process. In section 3, we give an overview on the development and the status-quo of publicly funded R\&D co-operations in Germany. Section 4 deals with a microeconometric study on the research productivity (measured by patents) of German firms. The main issue of our analysis is to distinguish the patenting behavior of three different groups of firms: (i) non-collaborating companies, (ii) collaborating firms which are involved in publicly funded R\&D consortia, (iii) firms 
with only privately financed $R \& D$ collaborations. We study whether $R \& D$ collaborations lead to higher research output. This would support the hypothesis that knowledge flows among partners emerge and positive spillovers are generated. Moreover, we investigate if publicly funded firm collaborations differ from collaborations which are privately financed.

\section{Theory and empirical perspectives on $R \& D$ collaborations and policy}

The impact of R\&D policies on firms' innovation behavior has been of interest in the economic literature for decades. The predominant question investigated is whether public subsidies crowd-out private investment. David et al. (2000) survey microeconomic and macroeconomic studies on that topic. ${ }^{1}$ Fewer studies deal with public policies and the change in other aspects of firms' innovation behavior, like cooperation, and innovative output. The survey by Klette et al. (2000) includes examples of microeconometric studies dealing with questions different from the crowding-out effect.

The question how and why firms engage in collaborations, partnerships, alliances, joint ventures and networks emerged during the 1980s in economic literature. Different theories and empirical studies have analyzed the mechanisms within research consortia and their benefits. Important contributions have been provided by Katz (1986), d'Aspremont/Jacquemin (1988), Freeman (1991), Kamien et al. (1992), Katsoulacos/Ulph (1998), Robertson/Gatignon (1998), Kamien/Zang (2000), and Cassiman/Veugelers (2002).

Link et al. (2002) and Hagedoorn et al. (2000) give an overview of strategic research partnerships, taking public financial support to firms into account. Hagedoorn et al. identify three broad categories explaning why firms enter into research partnerships: (a) transaction cost theory, (b) strategic management theory and (c) industrial organization theory. In transaction cost theory, R\&D cooperations are explained as a hybrid form of organization between the market and the hierarchy to facilitate an activity specifically related to the production and dissemination of technological knowledge. Due to the lacking appropriability of $R \& D$, positive external effects are generated. In order to internalize such effects, companies prefer to engage in research collaborations with possible third party users of their research results. In the strategic management theory, research partnerships are explained by a competitive reasons (common defensive position against competitors), by strategic networks (economies of scale and scope), by a resource based view of the firm (to exploit unique capabilities), by dynamic capabilities (to combine competencies) and by strategic options to new technologies (to determine resources for superior future performance). In the theory of industrial organization, research collaborations are explained by the existence of market failures due to the perceived public good nature of knowledge. The majority of theoretical studies deal with imperfect appropriable R\&D and an increase 
of market power. Bayona et al. (2001) review similar reasons to explain co-operation: (i) the reduction and sharing of uncertainty and costs, (ii) motivations relating to market access and the search for opportunities, (iii) size and R\&D capacity as characteristics of the firms. ${ }^{2}$

Recent empirical studies have established that contractual forms of $R \& D$, such as joint $R \& D$ has become a very important mode of inter-firm and science-firm collaboration as the number of partnerships has largely increased (Sakakibara, 1997; Hagedoorn/Narula, 1996). Sakakibara (2001) analyzed Japanese Government-sponsored R\&D consortia over 13 years and found evidence that the diversity of a consortium is associated with greater $R \& D$ expenditure by participating firms. The results support the thesis that spillover effects occur. The magnitude of the effect of the participation in an R\&D consortium on firm R\&D expenditures is found to be nine percent, on average. Branstetter/Sakakibara (2002) examine the impact of government-sponsored research consortia on the research productivity in Japan by measuring their patenting activities over time. They find evidence that participants of research consortia tend to increase their patenting after entering a consortium, which is interpreted as evidence for spillovers. The marginal increase of participants' patenting in targeted technologies, relatively to the control firms, is large and statistically significant.

In summary, empirical studies usually analyze vertical and horizontal R\&D co-operations or formal and informal arrangements. Just a few articles and empirical investigations deal with R\&D co-operations as a part of firm's innovative behavior and as a policy instrument. Sakakibara (1997) concludes that cooperative R\&D has been examined empirically by only a few studies and comprehensive empirical research is almost non-existent. Most treatments have been based on case studies or on the account of a few highly publicized co-operative R\&D projects which are not representative.

\section{Publicly funded R\&D co-operations in Germany}

European $R \& D$ co-operations originate from technology policy in the 1950s. At this time, when the European economic and technological development was far behind the USA, governments asked how to catch up in future technologies. Especially the business sector worried about a technological dependence from the USA and feared that Europe may end up as a low-tech producer in the long run. It was common sense that Europe even runs the risk of being just a consumer of American technologies rather than becoming a competitor. In these times, nuclear power was the most important technology and a chance to become technological independent was a political and industrial model of co-operation among institutions. On March, $25^{\text {th }}$ 1957, Belgium, Germany, France, Italy, Luxembourg and the Netherlands

\footnotetext{
${ }^{1}$ More recent studies are, for example, Wallsten (2000), Lach (2002) and Almus/Czarnitzki (2003).

${ }^{2}$ Further theoretical arguments to questions related to research partnerships can be found e.g. in Vonortas (1997) or in de la Mothe/Link (2002).
} 
signed the contract of the European Nuclear Community (EURATOM). The target of this community was international co-operation and knowledge transfer in nuclear sciences. This has been the first European approach for specific R\&D project networking. Afterwards, the number of publicly funded $R \& D$ areas increased rapidly. Governments offered programs to foster private and public R\&D activities in various fields, like ocean and polar research, climate and atmospheric research, research in the service of health, geosciences, building etc. R\&D policy was not introduced to promote complex R\&D networks, but big science in individual firms or individual public institutions. In this funding atmosphere, big companies were privileged because of their large absorptive capacity in light of their extensive know-how in forward-looking technologies.

At the beginning of the 1980s, researchers and policy makers realized that innovative and successful companies rely on alliances, SMEs as subcontractors and intensive co-operations with academics. The success and the exploitation of $R \& D$ projects was expected to be more efficient if many partners were involved and for that reason governments were thinking about best practices to stimulate R\&D cooperations. Japan was the most popular example of public efforts to foster R\&D co-operation, because its hardware industry succeeded in the "Very Large Integration Project" (VLSI) towards the US world market leadership IBM. The success of this project was attributed to temporary alliances of big companies, SMEs, universities and public laboratories. R\&D activities of all project partners were financed in a cost sharing agreement between public authorities and private organizations. The first imitator of this R\&D collaboration strategy was the USA, which followed with the well known industry co-operation program SEMATECH in 1987 (cf. de la Mothe/Link, 2002).

With respect to international experiences in $R \& D$ co-operations, Germany adapted this concept intensely, too. Besides the argument of an important international trend in the field of innovation, critics of a distorting competition caused by individual funded R\&D activities has led to the new approach of collaborative $R \& D$ subsidies. From now on, the German Government's view in the conditions for research promotion in industry were only met in those cases where companies were unable to develop certain technologies on their own - or where they could not do fast enough or not to an adequate extent. The new co-operative policy instrument was added, but did not substitute individual R\&D grants. Figure 1 illustrates this development of R\&D policy impressively. 
Figure 1:

Directly funded R\&D projects by the German Federal Government 1980-2001

Numbers of directly funded individual and collaborative projects

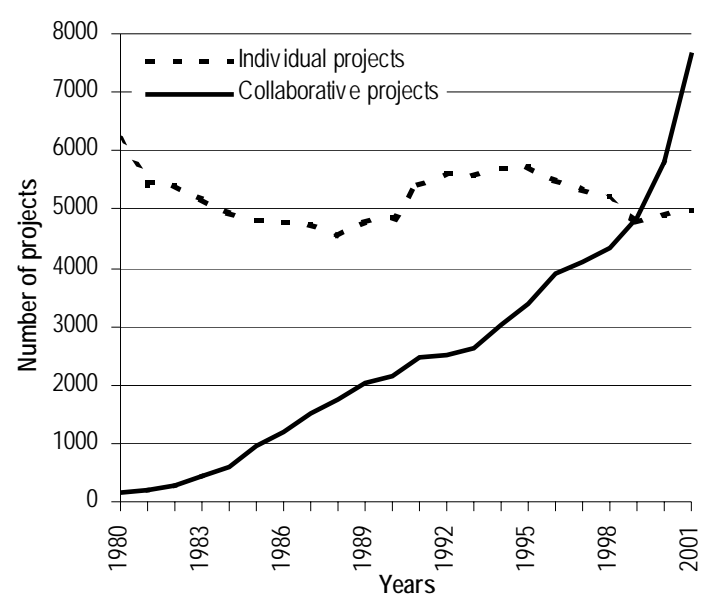

Source: BMBF-Project Database PROFI - Own calculation.
Total amounts of directly funded collaborative projects by technology priorities (in Mill. Euro)

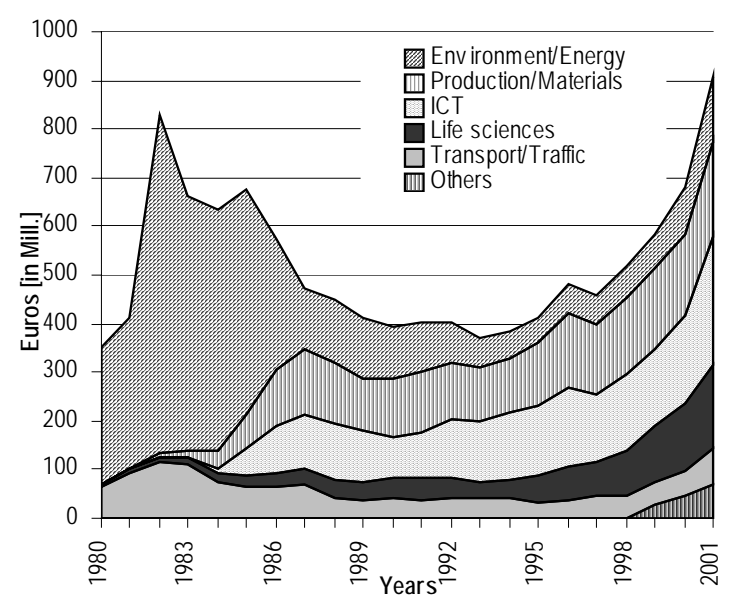

Source: BMBF-Project Database PROFI - Own calculation.

The peak of the amount of collaborative research in energy technologies in the early 1980s in Figure 1, results from just a handful firm consortia that were funded to conduct collaborative R\&D to build nuclear power stations and to bring these plants into operation. Co-operation was just necessary due to the huge size of these projects, but it was not guided by the same motivations as the modern collaborative network funding. More comparable with todays policies on collaborative research were other fields at the beginning of the 1980s: Product engineering and materials research were one of the first technology areas which had been rearranged in their R\&D funding procedures from individual to collaborative funding. Several projects of these two funding priorities are very close to industry and applied sciences while other technology fields are more related to basic sciences. Another reason cited for R\&D-co-operations is because the competition in these fields of technology have been much higher than in tight oligopolistic R\&D fields, like nuclear sciences, space sciences or ocean research. With respect to the principle of subsidiarity the German Government changed its funding philosophy towards pre-competitive and co-operative R\&D sponsoring. Some years later information and communication technologies (ICT) converted from monopolistic sciences carried out in large multinationals into a broadly used multi-purpose technology. In these times, Government was afraid that an ongoing individual R\&D funding may result in similar market distortions as suspected by public sector critics in other funding areas. Because of a large number of new technology firms which aligned their R\&D activities in these technology fields, R\&D policy makers reacted immediately and preferred collaborative research projects, too (cf. Fier, 2002).

In the mid nineties, Germany has opened a further chapter in research policy by stimulating competitive $R \& D$ networks. These new competitive network approaches changed the traditional selection process in which public authorities fixed the broad field of research by introducing contests: In a first stage of the funding process, participants set tasks in the framework of well defined technological areas (e.g. biotechnology, mobility in conurbation, nutrition etc.). Afterwards, independent expert jurors identify 
the best concepts and the most promising solutions. The winners are given the opportunity to submit detailed projects drafts and compete again. At this stage, other potential network-partners such as small and medium enterprises (SMEs) may apply to the winners for inclusion in a project. Eligible for participation in these contests are industrial enterprises, scientific institutions or public sector institutions which should submit a verifiable and feasible concept for co-operation and the commercialization of innovative ideas. Firms and universities, research institutions and users are requested to form consortia and co-operate in regional and/or thematic networks. Furthermore, R\&D co-operations in technologies like ICT and Life Sciences became more significant in the 1990s. In context with "multi-purpose" technologies the number of firms which applied for public grants grew substantially while the German Government faced R\&D budget restrictions at the same time. Due to the conviction of positive impacts of R\&D co-operations, the policy orientation changed to foster collaborations among applicants even more. It is less expensive and more effective in terms of numbers of potential recipients to subsidize R\&D networks in contrast to support single R\&D projects. However, individual project funding is still high because of costly $R \& D$ projects in space technology, large scale equipment for basic research and marine technology.

Today collaborative R\&D projects imply the sharing of resources, usually by project-based groups of researchers from each involved participant. The type and number of partners is not pre-determined by public authorities. Applicants for direct R\&D subsidies are free in their decisions concerning partners, contracts and relationships (c.f. BMBF, 2000 and BMBF, 2003). All partners agree to share their R\&D results and the right of use of all the knowledge generated within the co-operation. Labor costs, current operating expenditure, expenditure on fixed assets are cost-shared between the partners and the granting institution of the Federal Government. Network contests are an imporatnt part of the recent funding philosophy. R\&D policy is able to invest its budget more effectively by an increasing number of recipients and by improving its political awareness (cf. Fier/Harhoff, 2002).

Finally, note that there are no tax incentives for R\&D in Germany which means that the direct project funding is currently the most important instrument of R\&D policy.

\section{Empirical analysis of patenting behavior}

Along with the scientific value and the knowledge acquired, the primary objective of German public $R \& D$ funding is to make the most effective and efficient commercial use of R\&D results. In international statistics the innovative capacity is often measured by patents (cf. OECD, 1994, or Griliches, 1990, for comprehensive discussions on the use of patents as science and technology indicators). Patents play a key role in the innovation process, not only as an instrument to protect inventions but also as a source of information for the planning an implementation of R\&D. A disadvantage of using patents is that we are not able to perform a cost-benefit analysis as patents do not directly correspond to an economic value that can be quantified in currency units. It would be desirable 
to take into account other innovation indicators (e.g. sales with new products or cost reductions) or measures of firm performance (e.g. profits, productivity, growth) as well, but due to possibly long lags between the research projects and their economic benefits different from patent applications, such an analysis would require longer time-series data that currently do not available for German firms.

The German Federal Government mentions the development of patents, licensing and commercialization of $R \& D$ in its funding procedures. When an $R \& D$ recipient files an application, he/she already has to submit a plan for the utilization - initially in form of an outline which subsequently will become more and more detailed. All publicly funded R\&D recipients are expected and encouraged to assume responsibility for their commercialization management. In order to give an incentive to the grant recipients, the Federal Government allows firms to keep the research results secret and to benefit from all its returns for at least two years. However, if recipients do not apply for a patent within two years after completion of the research, the R\&D results become public (BMBF, 2000).

In this section, microeconometric analyzes of firms' patenting behavior are conducted. We investigate how different firm characteristics affect the probability to file at least one patent application as well as future patent applications. Futhermore, the number of granted patents are considered. We distinguish three groups of innovating companies: first, firms that did not participate in any collaborative innovation network. Second, we are able to identify firms which have not received public R\&D funding but are involved in R\&D co-operations. And third we consider those firms which participate in publicly funded R\&D networks from the German Federal Government. If significant spillovers are produced by collaborative research activities, we hypothesize that firms participating in R\&D networks will exhibit a higher propensity to patent than other enterprises and expect that $R \& D$ co-operations show a higher productivity in terms of patent application due to positive spillover effects. However, it is unclear how publicly funded research networks differ from privately financed collaborations. On one hand, it may be possible that public R\&D networks are less productive. It could be the case that the focus on cooperative research of modern public technology policies forces firms to collaborate in order to receive public grants. If the supply of policy schemes would had been different, those firms may well have preferred to keep their knowledge secret and conduct only research projects on their own. In this case, the publicly funded R\&D networks will not benefit from spillovers as firms pursue secrecy of their research and do not interact with their research partners involved in the project. On the other hand, the publicly funded networks and the partners involved may exhibit a "higher quality" of the research carried out as the research projects have passed the governmental quality control. Non-public R\&D cooperations could have failed in such a process or only dealt with less important research with respect to technological progress. 


\subsection{Data}

In order to perform an empirical analysis as described above, we link company information from three different databases: the Mannheim Innovation Panel (MIP), the Federal Government's Project Funding Information Database (PROFI) database and patent data from the German Patent Office (DPMA). The MIP is an annual innovation survey which is conducted by the Centre for European Economic Research (ZEW) on behalf of the Federal Ministry of Education and Research since 1993. In 1993, 1997 and 2001, the MIP represented the German part of the European Community Innovation Survey (CIS) of the European Commission. The data cover the manufacturing sector and selected service sectors like trade, transport, financial services, computer and telecom services, real estate, renting and other business services, especially including technical and R\&D services.

The PROFI database covers the civilian R\&D funding of the German Federal Government. In 2000, the Federal Government's R\&D expenditure in the business sector amounted to $€ 2,025$ Mill. This figure breaks down as follows: $27 \%$ were provided by the Federal Ministry of Education and Research (BMBF), 24\% by the Federal Ministry of Economics and Labour (BMWA), 45\% by the Federal Ministry of Defence (BMVg) and 3\% by other government departments (BMBF, 2002). The PROFI database includes reliable information on all projects and recipients funded by the BMBF and BMWA since 1980, i.e. almost all subsidized civilian R\&D projects are covered. The database permits an analysis of expenditure in terms of research themes, projects, recipients, funding procedure etc.

Finally, we extract information on patents from the German Patent Office (DPMA) database which contains the patenting activities in Germany since 1980. As both the DPMA and the PROFI databases are a census, our sample is determined by the MIP. We use three waves of the MIP, because only those contain a question on R\&D co-operations: 1993, 1997 and 2001, i.e. the surveyed information corresponds to the years 1992, 1996 and 2000. Note that the term "innovation panel" is misleading in this case, because we can only perform pooled cross-sectional analyzes rather than panel econometric approaches dealing with firm specific fixed or random effects. The main reason for the cross-sectional structure of the data is not market entry and exit during the sample period, but the low response rates in German surveys compared to international standards. Many firms are reluctant to publish information voluntarily and therefore participate irregularly in surveys like the MIP which usually yields a response rate of about 20 to $25 \%$ of contacted interviewees. After elimination of data sets with missing values in variables of interest, our sample consists of 4,132 observations referring to 3,568 different innovating firms (see Eurostat/OECD, 1997: 47, for the definition of an innovating firm). About 86\% of firms are only observed once in these three selected waves of the MIP. It is noteworthy that we have excluded a 
few sectors (on basis of the $\mathrm{NACE}^{3}$ three digit level) where no firm with participation in an publicly funded R\&D network has been present (especially some service sectors did not include such firms).

\subsection{Empirical considerations}

The dependent variable in the empirical analysis is a dummy variable $P A T_{i t}$ indicating whether the particular firm has filed at least one patent application in recent three years. ${ }^{4}$ For about $37 \%$ of firm observations PAT indicates at least one application. It may be possible that firms utilize their research results later than in the period of the receipt of public funding. The German guidelines on R\&D funding lay down that recipients are expected to utilize their research results within a two-year period after completion of the subsidized project. Otherwise the results have to be published to provide the knowledge to other researchers, and the subsidized firms lose their property rights. Due to this incentive, we also investigate future patent applications. The dummy $L E A D P A T_{i t}$ indicates whether firm $i$ will file at least one patent in year $t+1$ or $t+2$. This dummy shows that a share of $28 \%$ of firms will file a patent in the next two years. This is consistent with the mean of PAT as this covers three years and LEADPAT only two. In a further extension of the analysis we also consider the number of granted patents $\left(P G R A N T_{i t}\right)$ in section 4.4 , but due to some data restrictions (the time lag between application and granting date) we start with PAT and LEADPAT only.

As described above, the focus of the exogenous variables is basically two dummy variables: from the MIP survey, we use information whether a firm has joint any collaborative R\&D project in recent three years. Collaboration in this context means the active collaboration of all partners involved in the project. The mere contracting-out of R\&D is definitely excluded from this definition. By combining this information with the publicly funded research consortia from the PROFI database, we are able to identify whether a firm has participated at least in one subsidized R\&D co-operation or if it has only undertaken privately financed $R \& D$ co-operations in recent three years. The share of firms performing collaborative research is almost $40 \%$ which breaks down into $31 \%$ of privately financed collaborations and $9 \%$ of subsidized ones. We create the dummy $N F C O L_{i t}$ for non-funded collaborations and $S U B C O L_{i t}$ for subsidized arrangements. Additionally we include a dummy $S U B S O L E_{i t}$ which indicates whether a firm has received grants in non-collaborative research projects. Four percent of firms have received public grants in individual $R \& D$ projects. The inclusion of this variable prevents a bias stemming from additional funding in solely conducted research.

\footnotetext{
${ }^{3}$ NACE is the European standard sectoral classification of business activities.

${ }^{4}$ The "recent three years" terminology in the questionaire is common practice in the European CIS. While we can arrange the information from the PROFI and the DPMA database (subsidies and patents) as we like, we have to rely on the structure of the questionnaire in the MIP for several variables. A decomposition into one-year periods is not possible for some measures. Therefore, we merge the databases on basis of the corresponding three year periods.
} 
We use other variables to control for firm heterogeneity. Of course, we include firm size measured as the log of the number of employees $L N E M P_{i t}$. Since Schumpeter's seminal thoughts about innovation (see Schumpeter, 1934; Schumpeter, 1942), it is indisputable that firm size has an impact on innovative activities, e.g. such as patenting. $L N E M P^{2}$ is also included to allow for non-(log)linearity. Additionally to firm size, we use firms' age as explanatory variable. On one hand, with given size very young firms may be more likely to patent because spin-offs from larger firms or research institutions typically involve innovative ideas which are then protected by intellectual property rights. In contrast to this, older firms may show a higher likelihood to patent, because they could have undertaken continuous research which only pays off after several years of studying and experimenting.

Moreover, the patent stock $P S_{i t}$ is computed from the time-series of patent applications in the DPMA data by the perpetual inventory method:

$$
P S_{i t}=(1-\delta) P S_{i, t-1}+P A_{t}
$$

where $P A$ denotes the number of patent applications and $\delta$ represents the depreciation rate of knowledge assets and is set to $\delta=0.15$ (see e.g. Hall, 1990). The initial value of PS in 1980 is set to zero. The bias arising from this assumption should be negligible, because the patent data are available since 1980, but the period under review in the regressions starts in 1990. The patent stock controls for the variation of the propensity to patent among firms and enters the regression as lagged value LAGPS, that is prior to the corresponding three periods of the dependent variable PAT. We divide LAGPS by the number of employees to avoid collinearity among regressors. In addition to previous patenting activities, the current potential to patent does clearly depend on current R\&D engagement of firms. We measure this as the number of R\&D employees divided by EMP to reduce collinearity (share of R\&D employees: SRDEMP), and also include the squared value. $72 \%$ of firms in the sample have at least one R\&D employee.

All regressions include a dummy which denotes Eastern German firms as those may behave different due to the still ongoing transformation process of the Eastern German economy. Moreover, 15 sector dummies on basis of the NACE classification should capture different technological opportunities among business sectors. In principle, these dummies are created according to the NACE two-digit sectoral classification. However, some sectors are merged due to a low number of observations. Finally, two time dummies reflect changes in patenting activities over time. See Table 1 for descriptive statistics of the variables and Table 2 for correlations. 
Table 1: Descriptive Statistics (4,132 obs.)

\begin{tabular}{lccccc}
\hline Definition & Variable & Mean & Std. Dev. & Min. & Max. \\
\hline Patent application (dummy) & PAT & .367 & .482 & 0 & 1 \\
Future patent applications (dummy) & LEADPAT* & .281 & .450 & 0 & 1 \\
Number of granted patents & PGRANT* & 4.239 & 24.853 & 0 & 687 \\
log(employees) & LNEMP & 4.896 & 1.728 & 1.609 & 13.010 \\
Share of R\&D employees & SRDEMP & 0.105 & 0.209 & 0 & 1 \\
Lagged patent stock divided by employees & LAGPS/EMP & 0.015 & 0.044 & 0 & 0.484 \\
Non-funded collaborateurs (dummy) & NFCOL & 0.306 & 0.461 & 0 & 1 \\
Public funding in solely conducted research & SUBSOLE & 0.044 & 0.205 & 0 & 1 \\
projects (dummy) & & & & & \\
Participation in public research consortia & SUBCOL & 0.093 & 0.290 & 0 & 1 \\
(dummy) & EAST & 0.311 & 0.463 & 0 & 1 \\
Firms located in Eastern Germany (dummy) & LNAGE & 2.762 & 1.226 & 0 & 5.278 \\
log(firm age) & & &
\end{tabular}

* Only 3,331 observations (from 1992 and 1996).

Table 2: Correlation Matrix (4,132 obs.)

\begin{tabular}{|c|c|c|c|c|c|c|c|c|c|c|}
\hline & $P A T$ & $\begin{array}{l}\text { LEAD- } \\
P^{*}{ }^{*}\end{array}$ & PGRANT* & LNEMP & $\begin{array}{l}\text { SRD- } \\
\text { EMP }\end{array}$ & $\begin{array}{c}\text { LAGPS/ } \\
E M P\end{array}$ & $\begin{array}{l}N F- \\
\mathrm{COL}\end{array}$ & $\begin{array}{l}\text { SUB- } \\
\text { SOLE }\end{array}$ & $\begin{array}{l}\text { SUB- } \\
\text { COL }\end{array}$ & EAST \\
\hline LEADPAT* & 0.42 & 1.00 & & & & & & & & \\
\hline PGRANT* & 0.20 & 0.26 & 1.00 & & & & & & & \\
\hline LNEMP & 0.38 & 0.36 & 0.30 & 1.00 & & & & & & \\
\hline SRDEMP & 0.14 & -0.06 & 0.05 & -0.18 & 1.00 & & & & & \\
\hline LAGPS/EMP & 0.30 & 0.23 & 0.24 & 0.04 & 0.15 & 1.00 & & & & \\
\hline NFCOL & 0.16 & 0.11 & 0.06 & 0.16 & 0.07 & 0.02 & 1.00 & & & \\
\hline SUBSOLE & 0.14 & 0.09 & 0.17 & 0.15 & 0.15 & 0.09 & -0.01 & 1.00 & & \\
\hline SUBCOL & 0.24 & 0.11 & 0.16 & 0.13 & 0.23 & 0.20 & -0.21 & 0.31 & 1.00 & \\
\hline EAST & -0.22 & -0.15 & -0.10 & -0.27 & 0.06 & -0.09 & -0.01 & -0.02 & -0.03 & 1.00 \\
\hline LNAGE & 0.25 & 0.19 & 0.14 & 0.37 & -0.07 & 0.08 & 0.02 & 0.04 & 0.05 & -0.63 \\
\hline
\end{tabular}

* Only 3,331 observations (from 1992 and 1996).

There is no strong correlation among regressors except between LNAGE and LNEMP which amount to 0.37. Older firms will naturally maintain more personnel than start-ups or younger firms entering in a phase of expansion. Moreover, EAST is negatively correlated with firms' age. This stems from the German re-unification in 1990. Most firms in Eastern Germany have been newly founded when Eastern Germany became a market economy.

\subsection{Estimation of Probit Models}

We estimate Probit models on the likelihood of at least one patent application and consider a homoscedastic model and a heteroscedastic model. We performed $L M$ tests and $L R$ tests which show that heteroscedasticity is present (see e.g. Greene, 2000: 829-831). The heteroscedasticity is modeled groupwise multiplicatively with industry dummies, time dummies and firm-size dummies. However, tests have indicated that the use of industry dummies and size dummies suffice. As shown in Table 3, we 
find interesting results: collaborating firms (see $N F C O L$ and $S U B C O L$ ) exhibit a significantly higher probability to file a patent than non-cooperating firms. Moreover, the coefficient of the dummy indicating subsidized co-operations is even higher than the one indicating non-funded co-operations. This may represent a hint that the subsidized collaborations often deal with key technologies which are important for future inventions. Non-funded collaborations do possibly deal with less important research topics which do not as frequently generate patentable knowledge as subsidized collaborations.

Table 3: Probit estimations on patent applications (PAT)

\begin{tabular}{lcccc}
\hline & \multicolumn{2}{c}{ Homoscedastic Probit } & \multicolumn{2}{c}{ Heteroscedastic Probit } \\
& \multicolumn{1}{c}{ Coeff. } & Std. err. & Coeff. & Std. err. \\
\hline LNEMP & $0.25 * * *$ & 0.09 & $0.55^{* * *}$ & 0.10 \\
LNEMP & 0.01 & 0.01 & $-0.02 * * *$ & 0.01 \\
SRDEMP & $4.26 * * *$ & 0.44 & $4.26 * * *$ & 0.78 \\
SRDEMP & $-3.43^{* * *}$ & 0.43 & $-3.62 * * *$ & 0.70 \\
LAGPS/EMP & $7.08 * * *$ & 0.63 & $7.01 * * *$ & 1.14 \\
NFCOL & $0.35 * * *$ & 0.05 & $0.26 * * *$ & 0.06 \\
SUBSOLE & 0.12 & 0.13 & 0.04 & 0.10 \\
SUBCOL & $0.59 * * *$ & 0.09 & $0.43 * * *$ & 0.10 \\
EAST & $-0.35 * * *$ & 0.07 & $-0.33 * * *$ & 0.08 \\
LNAGE & $0.07 * * *$ & 0.03 & $0.04 *$ & 0.02 \\
Const. & $-2.83 * * *$ & 0.26 & $-3.25 * * *$ & 0.46 \\
\hline
\end{tabular}

Log-Likelihood

$-1,800.56$

Pseudo $R^{2}$

\# of obs.
$-1,768.51$

0.3487

*** $(* *, *)$ indicate a significance level of $1 \%(5,10 \%)$ in two-tailed t-tests. All estimations include 14 industry dummies and two time dummies. The heteroscedasticity is considered groupwise multiplicatively and is modeled with size and industry dummies.

The other results in Table 3 reveal the expected effects of the control variables. Larger firms are more likely to file a patent. Moreover, the stock of previous patents LAGPS is positively significant and firms with a high share of $R \& D$ employees exhibit a higher propensity to patent. However, if the share of R\&D employees exceeds $60 \%$ roughly, the probability to patent decreases. There are some firms in the sample that have a higher share of R\&D employees. These are usually small firms in high-tech sectors which may prefer secrecy instead of patenting, because with the patent disclosure their knowledge assets become public, at least partly. ${ }^{5}$ Another interesting result is that firms which receive public funding for solely conducted R\&D do not show a higher propensity to patent than other firms. This does also point to the hypothesis that collaboration generates positive spillover effects. Firms which receive public funding for R\&D have surely passed the "R\&D quality control" of the public authorities which have

\footnotetext{
${ }^{5}$ Patents are published in Europe after 18 months since the application even though patents may not have been granted yet (see e.g. OECD, 1994: 27).
} 
granted the funds. As even such firms show less patent activities than collaborating firms, positive spillover effects seem to be present in such networks.

We also computed marginal effects at sample means including standard errors obtained by the delta method which leads to the same conclusions. For example, engaging in privately financed collaborations increases the probability to patent by $12 \%$ (11\%) in the homoscedastic (heteroscedastic) model compared to not collaborating. The marginal effect of being a member in a publicly funded network amounts to $22 \%(18 \%)^{6}$

Table 4: Probit estimations on future patent applications (LEADPAT)

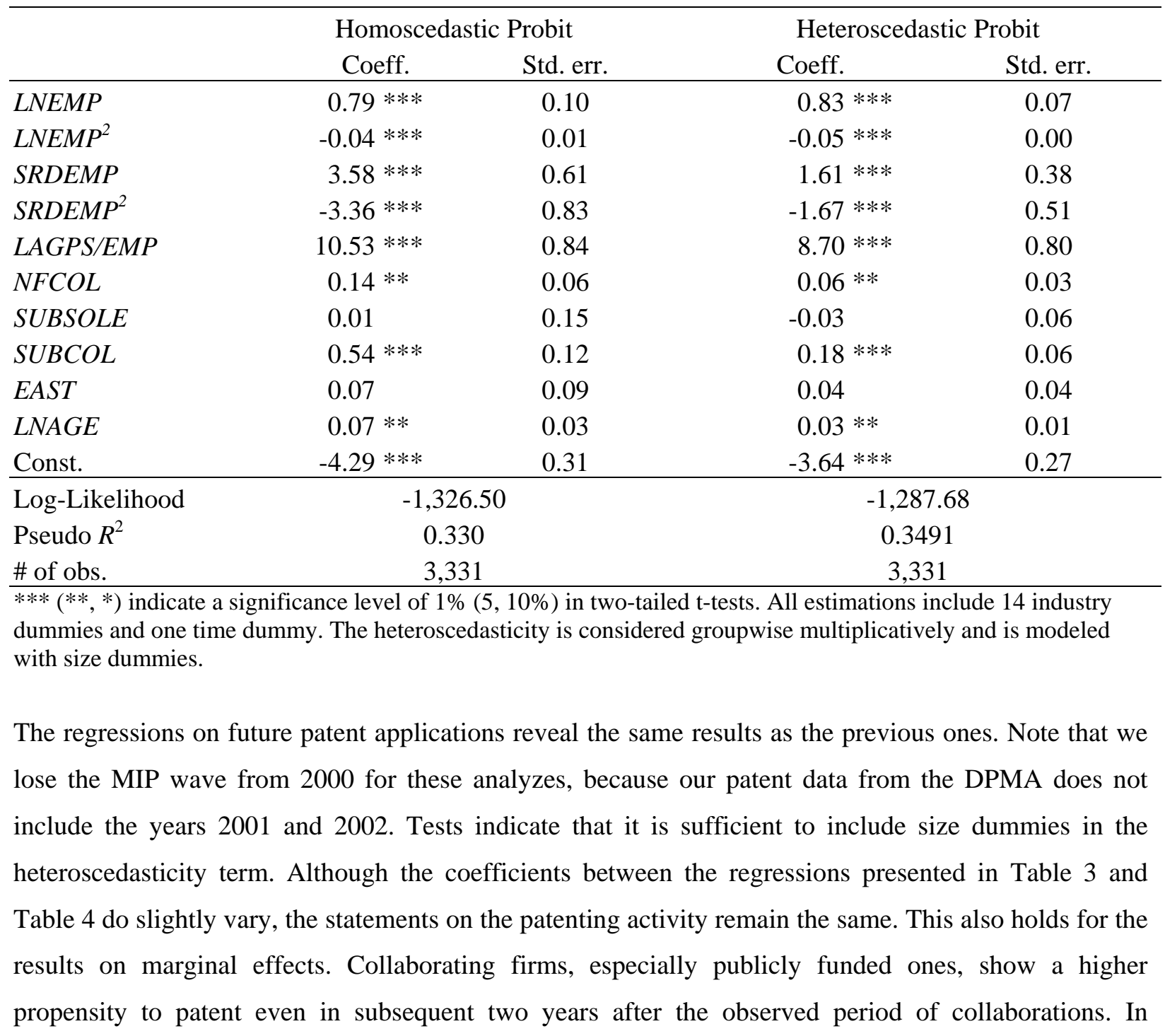

\footnotetext{
${ }^{6}$ A calculation of marginal effects for the discret change of the dummies from zero to one leads to very similar results.
} 
addition, it would be desirable to conduct a long-term time-series analysis, but this is not possible with the available data. ${ }^{7}$

\subsection{Extension of the analysis on counts of granted patents}

As final variable of interest we use not only a dummy on patent applications, but count the requests. However, the quality or economic value of patent applications may vary among firms. One possibility to improve the mere patent counts as a measure for valuable knowledge is to weight the applications with their citations (see Hall et al. 2001, for example). Unfortunately this is not possible with our data as long time series after the patent disclosure would be needed to count (or estimate) the future citations. Hence, we can only use the information on granted patents. We time the patent by its application date to avoid time lags between the undertaken research and the output indicator, but count just those applications as valuable research results that will be granted in the future. Due to the time lag between application and granting date (in the 1980s and early 1990s, for example, on average between 4 to 5 years depending on the year of application), we drop our MIP data from the year 2000 and use only the observations from 1992 and 1996.

In contrast to the U.S. where the majority of patent requests become granted patents usually, the ratio of applications to granted patents is different in Germany: For example, in 1996 (1992) only 44\% (70\%) of all patent applications were granted until 2000. Still we have to assume that patent applications which are not granted until 2000 have not been succesful. This leads to a downward bias for the year 1996 as there may be applications that will be granted after four years. Therefore this analysis should be interpreted carefully.

In view of this data, a count data model on the number of granted patents is estimated. We employ a Negative Binomial regression (see e.g. Greene, 2000, 886-887) instead of a Poisson model, because a likelihood ratio test indicated that the hypothesis on no overdispersion has to be rejected. The results of the previously estimated Probit models are confirmed by the regression on the number of granted patents (see Table 5). Collaborating firms which did not participate in publicly funded R\&D consortia hold more granted patents than non-collaborating firms on average. Furthermore, the members of publicly supported R\&D networks reveive even higher numbers of granted patents than other collaborating firms. Again, the results point to positive spill-over effects of collaboration.

\footnotetext{
${ }^{7}$ As a test on the robustness of the findings above, we also considered the same regressions for a subsample small and medium-sized firms with less than 250 employees. Those regressions yield similar estimates and confirm the conclusions drawn from the regressions with the full sample. The results are not presented, but are available from the authors upon request.
} 
Table 5: Negative binomial regression on the number of granted patents (PGRANT)

\begin{tabular}{lcc}
\hline & Coeff. & Std. err. \\
\hline LNEMP & $1.20^{* * *}$ & 0.17 \\
LNEMP & -0.02 & 0.01 \\
SRDEMP & $7.27^{* * *}$ & 0.99 \\
SRDEMP & $-7.43^{* * *}$ & 1.25 \\
LAGPS/EMP & $26.18^{* * *}$ & 1.71 \\
NFCOL & $0.21^{* *}$ & 0.10 \\
SUBSOLE & 0.24 & 0.21 \\
SUBCOL & $0.44^{* * *}$ & 0.17 \\
EAST & -0.12 & 0.15 \\
LNAGE & 0.08 & 0.05 \\
Const. & $-7.22 * * *$ & 0.56 \\
\hline
\end{tabular}

Log-Likelihood

Pseudo $R^{2}$

$-3,666.90$

\# of obs.

0.1954

*** $(* *, *)$ indicate a significance level of $1 \%(5,10 \%)$ in two-tailed t-tests. The estimation includes 14 industry dummies and one time dummy.

Although the previous results turn out to be quite stable in different settings, it is possible that the regressions are subject to a self-selection bias. Subsidized firms may substantially be different from other firms that a self selection into subsidized networks occurs. Moreover, the government follows a "picking-the-winner" strategy. The same may be true for collaborations in general. Firms will also apply "picking the winner" when searching for appropriate partners for joint R\&D activities. It is therefore questionable if such firms were less likely to apply for a patent if they had not participated in a publicly funded R\&D network. For this reason, we apply a non-parametric matching procedure in the following subsection which is able to account for selectivity.

\subsection{Estimation of Treatment Models}

\subsubsection{Matching and Identification}

The matching approach has been developed to identify treatment effects when the available observations on individuals or firms are subject to a selection bias. This typically occurs when participants in public measures differ from non-participants in important characteristics, for example (see Heckman et al., 1999; Heckman et al., 1997 for surveys).

The matching is able to address directly the question "What would a treated firm with given characteristics have done if it had not been treated?" A treatment in our context is the participation in an R\&D network. We distinguish collaborating and non-collaborating firms as well as subsidized and nonsubsidized collaborations. The matching estimator balances the sample with respect to the variables included in the matching procedure individually for each observation. The advantage over a parametric regression analysis such as Heckman's (1979) selection model is that one does neither have to assume a functional form of the equation of interest (the patenting behavior) nor one has to impose distributional 
assumptions on the relation between the selection equation and the patenting equation. A nice side effect of the matching for empirical applications is that one does not need an excluded variable from the second equation to identify the coefficients as it is usually necessary in selection models. Especially in the context of innovation at the firm level it is always difficult to find a variable whose inclusion in the selection equation but the exclusion in the equation of interest is theoretically well justified by an economic model. One disadvantage in comparison to selection models is that the matching takes only account of observable characteristics while the selection models allow for selection on unobservables.

The fundamental evaluation question can be illustrated by an equation describing the average treatment effect on the treated:

$$
E(\theta)=E(Y T \mid S=1)-E(Y C \mid S=1)
$$

where $Y T$ is the outcome variable, that is the propensity to patent in our case. The status $S$ refers to the group: $S=1$ is the treatment group and $S=0$ the non-treated firms. $Y C$ is the potential outcome which would have been realized if the treatment group $(S=1)$ had not been treated. The problem is obvious: while the outcome of the treated individuals in case of treatment, $E(Y T \mid S=1)$, is directly observable, it is not the case for the counterpart. What would these firms have realized if they had not received the treatment? $E(Y C \mid S=1)$ is a counterfactual situation which is not observable and, therefore, has to be estimated. In the case of matching, this potential outcome is constructed from a control group of nonparticipants. ${ }^{8}$ The matching relies on the intuitively attracting idea to balance the sample of program participants and comparable non-participants. Remaining differences in the outcome variable between both groups are then attributed to the treatment (Heckman et al., 1997).

Initially the counterfactual cannot simply be estimated as average outcome of the non-participants, because $E(Y C \mid S=1) \neq E(Y C \mid S=0)$ due to the possible selection bias. The participant group and nonparticipant group are expected to differ, except in cases of randomly assigned measures in experimental settings. Rubin (1977) introduced the conditional independence assumption (CIA) to overcome the selection problem, that is, participation and potential outcome are independent for firms with the same set of exogenous characteristics $X$. If this assumption is valid, it follows that

$$
E(Y C \mid S=1, X)=E(Y C \mid S=0, X)
$$

The outcome of the non-participants can be used to estimate the counterfactual outcome of the participants in case of non-participation provided that there are no systematic differences between both groups. The treatment effect can be written as

\footnotetext{
${ }^{8}$ There exist other approaches which are not applicable to our case like a difference-in-difference estimation, where participants and non-participants are compared before and after the treatment (see Heckmann et al., 1999, for example).
} 


$$
E(\theta)=E(Y T \mid S=1, X=x)-E(Y C \mid S=0, X=x)
$$

Conditioning on $X$ takes account of the selection bias due to observable differences between participants and non-participants.

\subsubsection{Estimation of the counterfactual}

A weight $w_{i j}$ is defined with respect to $X$ for each participant $i$ which assignes a high weight to nonparticipants $j$ being similar in $X$ and vice versa. The weights $w_{i j}$ sum up to one. The treatment effect for participant $i$ is

$$
Y T_{i}-\sum_{j} w_{i j} Y C_{j}
$$

The outcome of the treated individual $i$ is compared to the outcome of non-treatment of all nonparticipants $j$. According to Heckman et al. (1997) matching estimators differ with respect to the weights attached to members of the comparison group. The extreme cases are to use all non-treated individuals as control group or to pick just the most similar control observation. The latter case is called nearest neighbor matching. The weight would be equal to one for the most similar control observation and would be zero for all other cases. Nearest neighbor matching has already been applied in industrial economic literature to estimate the impact of R\&D subsidies on R\&D investment at the firm level (see Czarnitzki, 2001; Czarnitzki/Fier, 2002; Almus/Czarnitzki, 2003).

In this study, a kernel-based matching is applied. In contrast to the nearest neighbor matching where only one control observation is assigned to each participant, the entire group of non-participants is used for every participating firm. Therefore, a non-parametric regression in the sample of non-participants is performed to determine the weights for the potential non-treatment outcome. The weights are specified as

$$
\mathrm{w}_{\mathrm{ij}}=\frac{K\left(h^{-1}\left(X_{j}-X_{i}\right)\right)}{\sum_{j} K\left(h^{-1}\left(X_{j}-X_{i}\right)\right)}
$$

The kernel $K$ downweights observations with respect to their distance to $X_{i}$. $h$ is the bandwidth parameter. The weights are obtained by a non-parametric regression that is a locally weighted average of the outcome of the non-treated firms with similar characteristics. In this case, the Nadaraya-Watson kernel regression is applied (see Pagan and Ullah, 1999, section 3.2). The resulting estimator is

$$
\sum_{j} \frac{K\left(h^{-1}\left(X_{j}-X_{i}\right)\right)}{\sum_{j} K\left(h^{-1}\left(X_{j}-X_{i}\right)\right)} Y_{j}=\sum_{j} w_{i j} Y_{j}
$$


As one often wants to consider more than one matching criterion, one has to deal with the "curse of dimensionality". If we employ a lot of variables in the matching function, it will become difficult to find appropriate controls. Rosenbaum/Rubin (1983) suggested to use a propensity score as a single index and thus to reduce the number of variables included in the matching function to just one. Therefore a probit model is estimated on the collaboration dummy. The estimated propensity scores are subsequently used as matching criterion. Lechner (1998) introduced a modification of the propensity score matching as one often wants to include additional variables, e.g. like firm size, directly in the matching function. In this case, instead of a single $X$ (propensity score), other characteristics of the firms may be employed in the matching function. Therefore the Mahalanobis distance

$$
M D_{i j}=\left(X_{j}-X_{i}\right)^{\prime} \Omega^{-1}\left(X_{j}-X_{i}\right)
$$

is used as argument in the kernel function. $\Omega$ is the empirical covariance matrix of the vector $X_{j}$. Finally, the kernel function and the bandwidth have to be chosen. We use the Gaussian kernel $K=(\sqrt{2 \pi})^{-1} \exp \left(-0.5\left(h^{-1} M D_{i j}\right)^{2}\right)$ and the bandwith $h$ is chosen according to Silverman's (1986) rule of thumb as

$$
h=\left\{\begin{array}{l}
0.9 A n^{-1 / 5} \text { if } k=1 \\
k\left(0.9 n^{-1 / 5}\right)^{2} \text { if } k>1
\end{array}\right.
$$

where $k$ is the number of variables included in $X, n$ is the number of observations and $A=\min (s, i q r / 1.34)$ with $s$ as the standard deviation and iqr as the inter-quartile range of $X$ in the sample of non-participants.

The Nadaraya-Watson kernel regression is performed for every participant in the sample, that is, an estimate of the potential outcome for each $i$ is constructed from the entire sample of non-treated firms. Once the samples have been balanced by the kernel matching procedure, remaining differences in the outcomes are not due to previous heterogeneity in observable characteristics, but can be assigned to the treatment if no selection on unobservables occurs. The average effect on the treated can thus be calculated as the mean difference of the matched samples:

$$
\hat{\theta}=\frac{1}{n^{1}}\left(\sum_{i} Y T_{i}-\sum_{i} \widehat{Y C}_{i}\right)
$$

with $\widehat{Y C}_{i}$ being the estimated counterfactual for $i$ and $n^{1}$ is the sample size of treated firms. 


\subsubsection{Empirical application of the kernel-based matching}

We perform two applications of the matching estimator to consider a possible selection bias. First, we investigate whether collaborating firms are still more likely to apply for a patent than non-collaborating firms. Second, we analyze the group of collaborating firms only, in order to study if the collaborating firms which are publicly subsidized do still show a higher probability to patent than firms which only participate in privately financed collaborations.

As the matching relies on the idea of comparing similar observations, we decided to restrict the sample to companies with 5,000 employees at most, because it is not very meaningful to look for similar firms when they are larger than this threshold. Such huge companies are unique in the German economy. We consider a propensity score matching without other variables in the matching function, and estimate a Probit model on the collaboration dummy with these explanatory variables: $L N E M P$, its squared values, LAGPS/EMP, SRDEMP and its squared values, EAST, LNAGE as well as 14 industry and two time dummies. The observations of the matched control group are required to belong to the same year of observation as the participant. Therefore the weights $w_{i j}$ of potential controls from other years are set to zero during the matching procedure.

Table 6 shows the mean values of the considered characteristics of the different firm groups: collaborating firms as "treatment group" and non-collaborating firms as control group. We have 1,564 cooperating firms and 2,473 non-cooperating firms. As the t-tests indicate those firm groups differ significantly in size, in the share of R\&D employees, the patent stock and age. Moreover, the sectoral distribution is different (not presented in Table 6). Most important, the groups exhibit different propensity scores on collaboration. As the right column in Table 6 shows, the matching is successful. After the estimation of the control group all differences in exogenous characteristics vanish. However, the patent dummies PAT, LEADPAT and PGRANT still differ among groups. Despite controlling for a possible selection bias, collaborating firms are more likely to patent than others, that is we can attribute this circumstance to the fact of collaboration which again supports the hypothesis that positive spillover effects are generated in R\&D networks. On average, the treatment effect on the treated for applying for a patent amounts to $17 \%$. Furthermore, collaboration increases the number of granted patents by 0.82 on average. All treatment effects are significantly different from zero. 
Table 7: Mean differences in characteristics of collaborating firms:

subsidized collaborations versus non-funded collaborations

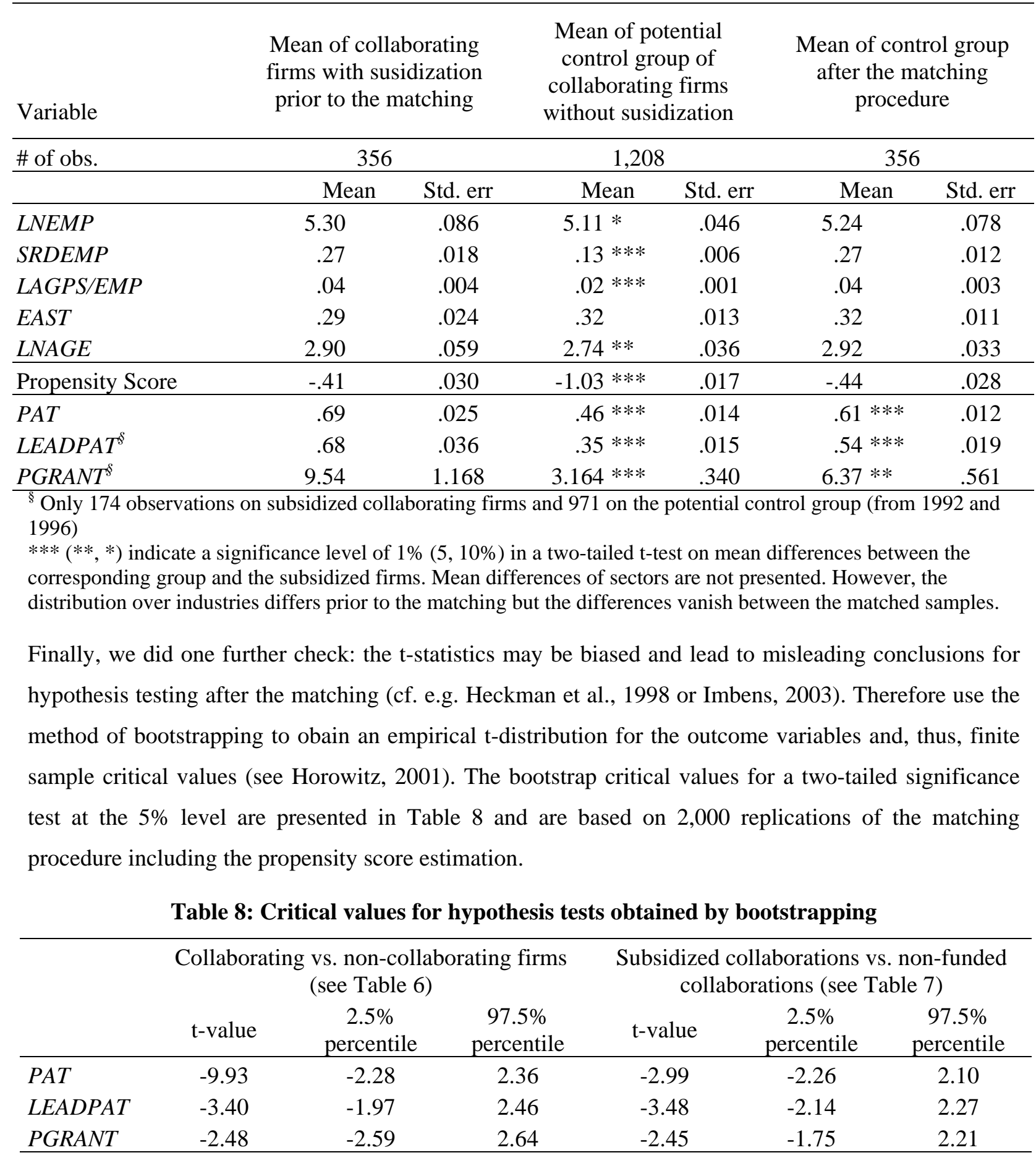

Although the lower critical values relevant for our tests are smaller than -1.96 (expect the one for PGRANT in the sample of collaborating firms which is actually larger), we can reject the null hypothesis of equal means in most cases. The only exception is for PGRANT in the sample of collaborating firms. The bootstrap critical value is -2.59 , but the t-value computed from the original sample is only -2.48 . Hence, we cannot conclude that privately financed collaborations leads to more granted patents at the 5\% significance level (However, this is still true for the $10 \%$ significance level.) The likelihood to patent measured by PAT and LEADPAT is still significantly different from zero at the $5 \%$ level. In the sample 
of collaborating firms, all hypotheses are confirmed after the bootstrapping. Firms that engage in publicly funded networks achieve on average more granted patents due to their network membership.

\section{Conclusions}

Since the beginning of the 1980s, publicly funded research networks are an important instrument in German technology policy. We observe an impressively increasing number of collaborative projects, especially in applied technological fields since 1990. Today, the funding of R\&D collaborations is an essential element of the German Government's technology policy. Our study has focused on the impact of this policies by analyzing the benefits of public incentives for $R \& D$ collaborations in terms of innovative output measured by patent indicators.

Our main hypothesis is in line with the literature on collaborative research, that spillovers are generated within R\&D co-operations. We distinguish non-collaborating firms from publicly funded R\&D cooperations and non-funded co-operations. It turns out that collaboration increases the likelihood to patent significantly. Firms in publicly funded networks are even more likely to apply for a patent than firms in private networks. These findings are supported by Probit regressions on a patent dummy and a dummy for future applications as well as a count data model on the number of granted patents. Moreover, the results also hold in econometric matching models which take account of a possible selection bias and are based on weaker assumptions. We apply a kernel-based matching and compare collaborating and noncollaborating firms as well as collaborating companies which received public grants and firms that did finance R\&D cooperations privately. Those results support the hypothesis that firms engaged in networks benefit from collaboration in terms of knowledge and technology transfer among partners which enables a more efficient or higher quality research.

One drawback of patents as an indicator is that they do not necessarily represent an economic value. It may be the case that recipients of public grants apply their successful result as a patent, to impress their sponsor (Federal Government) and their shareholders. Herein recipients of R\&D funds take future applications for R\&D grants into account and patenting might be a good strategy to convince funding authorities prior to the next application. However, some share of those additional patents may not corresponnd to any economic value. Another caveat of our finding may result from official requirements: Although patenting or licensing is not conditional, recipient firms are requested to utilize their research results by the Federal Government's funding conditions and patenting is, among others, one strategy to show a commercialization of research. We try to overcome this potential problem by using the number of granted patents. If the recipient firms would use also non-valueable research results to apply for patents, it is very likely that those applications would not result in granted patents in the end. However, we find that even the average treatment effect on the treated with respect to the number of granted patents is different among both groups of collaborating firms. Firms that are engaged in publicly sponsored networks received about three patents more than firms that collaborate on a privately 
financed basis only. Therefore, we conclude that the research undertaken in publicly funded networks increases research results substantially and thus economic value of the recipients knowledge capital.

As further research, a useful extension of our analysis could be weighting the patent counts with their future citations in order to control for the heterogeneity among patents in terms of their economic value. Another more powerful test of the causal relationship between research collaboration and its output would involve conducting a pre and post-collaboration analysis of patenting activities. However, such analysis is not possible with our cross-sectional structured database. Finally, it would be useful to distinguish between private-private and public-private partnerships in future research to get more knowledge about the origins of know-how, its transformation into products and processes and thus the efficiency of publicly funded R\&D networks.

\section{References}

Almus, M. and D. Czarnitzki (2003), The effects of public R\&D subsidies on firms' innovation activities: the case of Eastern Germany, Journal of Business and Economic Statistics 21(2), 226236.

Bayona, C., T. Garcia-Marco and E. Huerta (2001), Firms' motivations for cooperative R\&D: An Empirical Analysis for Spanish Firms, Research Policy 30, 1289-1307.

BMBF (2000), Report of the Federal Government on Research 2000, Bonn: Federal Ministry for Education and Research

BMBF (2002), Facts \& Figures Research 2002, Bonn: Federal Ministry for Education and Research.

BMBF (2003), Merkblatt für Antragsteller auf Projektförderung zur Gestaltung von Kooperationsvereinbarungen bei Verbundprojekten, Bonn: Federal Ministry for Education and Research

Branstetter, L. G. and M. Sakakibara (2002), When Do Research Consortia Work Well and Why? Evidence from Japanese Panel Data, American Economic Review 92(1), 143-159.

Cassiman, B. and R. Veugelers (2002), R\&D co-operation and spillovers. Some empirical evidence from Belgium, American Economic Review 92(4), 1169-1184.

Czarnitzki, D. (2001), Die Auswirkungen der Forschungs- und Technologiepolitik auf die Innovationsaktivitäten ostdeutscher Unternehmen, Schmollers Jahrbuch - Zeitschrift für Wirtschafts und Sozialwissenschaften (Journal of Applied Social Science Studies) 121(4), 539560.

Czarnitzki, D. and A. Fier (2002), Do innovation subsidies crowd out private investment? Evidence from the German Service Sector, Applied Economics Quarterly (Konjunkturpolitik) 48(1), 1-25.

d'Aspremont, C. and A. Jacquemin (1988), Cooperative and Nocooperative R\&D in Duopoly with Spillovers, American Economic Review 78(5), 1133-1137.

David, P.A., B.H. Hall und A.A. Toole (2000), Is public R\&D a complement or substitute for private R\&D? A review of the econometric evidence, Research Policy 29, 497-529.

de la Mothe, J. and A. N. Link (2002), Introduction, in: J. de la Mothe and A. N. Link, Networks, alliances and partnerships in the innovation process, Boston, Mass.: Kluwer Academic Publ., 36.

European Commission (2002), The sixth framework programme in brief. 
Eurostat and OECD (1997), OSLO-Manual: Proposed guidelines for collecting and interpreting technological innovation data, Paris.

Fier, A. (2002), Staatliche Förderung industrieller Forschung in Deutschland: Eine empirische Wirkungsanalyse der direkten Projektförderung des Bundes, Baden-Baden: Nomos-Verl.-Ges.

Fier, A. and D. Harhoff (2002), Die Evolution der bundesdeutschen Forschungs- und Technologiepolitik: Rückblick und Bestandsaufnahme, Perspektiven der Wirtschaftspolitik 3(3), 279-301.

Freeman, C. (1991), Networks of Innovators: A Synthesis of Research Ideas, Research Policy 20, 499514.

Greene, W. H. (2000), Econometric Analysis, New Jersey: Upper Saddle River.

Griliches, Z. (1990), Patent Statistics as Economic Indicators: A Survey, Journal of Economic Literature XXVIII, 1661-1707.

Hagedoorn, J., A. N. Link and N. S. Vonortas (2000), Research partnerships, Research Policy 29, 567586.

Hagedoorn, J. and R. Narula (1996), Choozing organisational modes of strategic technology partnering: international and sectoral differences, Journal of International Business Studies 27, 265-284.

Hall, B. H. (1990), The manufacturing sector master file: 1959-1987, NBER Working Paper, Cambridge, $M A$.

Hall, B.H., A. Jaffe and M. Trajtenberg (2001), Market Value and Patent Citations: A First Look, Working Paper No. E01-304, University of California, Berkeley.

Heckman, J. J. (1979), Sample Selection Bias as a Specification Error, Econometrica 47, 153-161.

Heckman, J. J., H. Ichimura and P. Todd (1997), Matching as an econometric evaluation estimator: evidence from evaluating a job training program, Review of Economic Studies 64(4), 605-654.

Heckman, J. J., H. Ichimura and P. Todd (1998), Matching as an econometric evaluation estimator, Review of Economic Studies 65, 261-294.

Heckman, J. J., R. J. Lalonde and J. A. Smith (1999), The economics and econometrics of active labor market programs, in: A. Ashenfelter and D. Card (eds.), Handbook of Labour Economics, Amsterdam, 3, 1866-2097.

Horowitz, J. (2001), The Bootstrap, in: J.J. Heckman and E.E. Leamer (eds.), Handbook of Econometrics 5, Elsevier Science B.V., 3159-3228.

Imbens, G.W. (2003), Semiparametric Estimation of Average Treatment Effects Under Exogeneity: A Review, Working Paper, UC Berkeley.

Kamien, M. I., E. Muller and I. Zang (1992), Research Joint Ventures and R\&D Cartels, American Economic Review 82(5), 995-1012.

Kamien, M. I. and I. Zang (2000), Meet Me Halfway: Research Joint Ventures and Absorptive Capacity, International Journal of Industrial Organization 18(7), 995-1012.

Katsoulacos, Y. S. and D. T. Ulph (1998), Endogenous Spillovers and the Performance of Research Joint Ventures, Journal of Industrial Economics 46(3), 333-357.

Katz, M. L. (1986), An Analysis of Cooperative Research and Development, RAND Journal of Economics 17(4), 527-543.

Klette, T.J., J. Møen und Z. Griliches (2000), Do subsidies to commercial R\&D reduce market failures? Microeconometric evaluation studies, Research Policy 29, 471-495.

Lach, S. (2002), Do R\&D subsidies stimulate or displace private R\&D? Evidence from Israel, Journal of Industrial Economics 50(4), 369-390. 
Lechner, M. (1998), Training the East German labour force: microeconometric evaluations of continuous vocational training after unification, Heidelberg.

Link, A.N. (2002), Private-sector and public-sector strategies to encourage technological alliances, in: de la Mothe and A.N. Link (eds.), Networks, alliances and partnerships in the innovation process, Boston, Mass.: 7-28.

Link, A. N., D. Paton and D. S. Siegel (2002), An analysis of policy initiatives to promote strategic research partnerships, Research Policy 31, 1459-1466.

OECD (1994), The measurement of scientific and technological activities. Using patent data as science and technology indicators: patent manual 1994, Paris.

OECD (2002), Innovative Networks: Co-operation in National Innovative Systems, Paris.

Pagan, A. and A. Ullah (1999), Nonparametric Econometrics, Cambridge: Cambridge University Press.

Robertson, T. and H. Gatignon (1998), Technology development mode: a transaction cost conceptualization, Strategic Management Journal 19, 515-531.

Rosenbaum, P. R. and D. B. Rubin (1983), The central role of the propensity score observational studies for causal effects, Biometrica 70, 41-55.

Rubin, D. B. (1977), Assignment to treatment group on the basis of covariate, Journal of Educational Statistics 2, 1-26.

Sakakibara, M. (2001), The Diversity of R\&D Consortia and Firm Behaviour: Evidence from Japanese Data, The Journal of Industrial Economics 49(2), 181-196.

Sakakibara, M. (1997), Evaluating government-sponsored R\&D consortia in Japan: who benefits and how?, Research Policy 26, 447-473.

Schumpeter, J. A. (1934), The theory of economic development, Cambridge, MA.: Harvard University Press.

Schumpeter, J. A. (1942), Capitalism, Socialism and Democrocy, New York: Harper and Row (Reprinted 1960).

Silverman, B. W. (1986), Density Estimation for Statistics and Data Analysis, New York: Chapman and Hall.

Vonortas, N.S. (1997), Cooperation in research and development (Economics of Science Technology and Innovation, Vol. 11), Boston: Kluwer Academic.

Wallsten, S.J. (2000), The effects of government-industry R\&D programs on private R\&D: the case of the Small Business Innovation Research Programm, RAND Journal of Economics 31(1), 82-100. 